\title{
Feldenkrais-Core Integration Method in Patients with Ankylosing Spondylitis: A Pilot Study
}

\author{
Susanna Maddali Bongi ${ }^{1 *}$, Guya Piemonte ${ }^{2}$, Khadija El Aoufy ${ }^{1}$ and Monica Landi ${ }^{3}$ \\ ${ }^{1}$ Department of Experimental and Clinical Medicine, University of Florence, Italy \\ ${ }^{2}$ Department of Experimental and Clinical Medicine, University of Florence, Italy \\ ${ }^{3}$ Associazione Multidisciplinare Riabilitazione Reumatologica, Italy
}

Submission: December 14, 2016; Published: January 03, 2017

*Corresponding author: Susanna Maddali Bongi, Department of Experimental and Clinical Medicine, Division Rheumatology, University of Florence, Largo Brambilla 3, 50134 Florence, Italy, Tel: +39-055-2751868; E-mail: susanna.maddalibongi@gmail.com

\begin{abstract}
Background: It is widely accepted that rehabilitation combined with pharmacological approach could improve pain, spinal mobility and functional status in ankylosing spondylitis (AS). Feldenkrais-Core Integration (FCI) method is a mind body therapy based on low impact exercises focusing on better body organization, postural re-education and balance improvement.

Aims: Our aim was to assess in a pilot study the utility and feasibility of FCI approach in the treatment of AS.

Setting: Outpatient Clinic of the Division of Rheumatology, Department of Experimental and Clinical Medicine, University of Florence.

Methods: Ten AS patients were recruited to perform a FCI physiotherapic program of 10 supervised group sessions (60 min, twice a week). Clinic and clinimetric measurements including pain, fatigue, global health status (VAS), disease effect on wellbeing (BAS-G), functional status (BASFI, HAQ-S), disease activity (BASDAI), enthesitis (MASES) and anthropometric measurements of lumbar mobility and cervical mobility were assessed at baseline $(\mathrm{t}=0)$ and at the end of the study $(\mathrm{t}=1)$. At $\mathrm{t}=1$ patients' satisfaction, attendance rate and attrition rate were assessed. Only descriptive statistics was performed.

Results: Our results showed improvements in pain, fatigue, global health status, BAS-G, BASFI, HAQ-S, MASES, BASDAI, lumbar lateral flexion and cervical range of motion (cervical forward flexion, extension, lateral flexion and rotation) at the end of the study compared to the baseline. Greater improvements in percentage are found in pain, fatigue, self perceived health status, functionality and tenderness on enthesial sites. No dropouts were registered.

Keywords: Ankylosing spondylitis; Rehabilitation; Mind body therapies; Feldenkrais-core integration

Abbreviations: AS: Ankylosing Spondylitis; BASDAI: Bath Ankylosing Spondylitis Disease Activity Index; BASFI: Bath Ankylosing Spondylitis Functional Index; BAS-G: Bath Ankylosing Spondylitis Global Score; CI: Core Integration; CNS: Central Nervous System; FCI: Feldenkrais-Core Integration; FFD: Finger Floor Distance; GPR: Global Posture Reeducation; HAQ-S: Health Assessment Questionnaire-Spondyloarthropathies; ISTAP: The Institute of Postural Analysis, Florence, Italy; MASES: Maastricht Ankylosing Spondylitis Enthesitis Score; MBT: Mind Body Therapies; NRS: Numerical Rating Scale; OSWDQ: Oswestry Low Back Pain Disability Questionnaire; SF36: Short Form 36 Health Survey; TNF: Tumor Necrosis Factor; VAS: Visual Analogue Scale; WDI: Waddell Disability Index
\end{abstract}

\section{Introduction}

Ankylosing spondylitis (AS) is a chronic, progressive, immunoinflammatory disease that predominantly affects the sacroiliac joints and the whole spine [1]. AS may be associated with extraspinal manifestations, such as peripheral arthritis, uveitis, and cardiovascular complications with functional impairment [2], disability and poor quality of life [3]. The estimated prevalence in european-caucasian population ranges from 0.1 to 1.4 [1], in Italy is about $0.37 \%$ [4]. AS is mainly characterized by chronic inflammatory sacroiliac pain, spinal stiffness, loss of motility of the spine and serious postural abnormalities.

Postural changes associated with AS include loss of lumbar lordosis, accentuation of the thoracic kyphosis, inversion of cervical lordosis and hip flexion [5]. Such condition may affect the global functional status and social wellbeing restricting interpersonal communication and basic activities of daily living [6]. Moreover, fixed thoracolumbar hyperkyphosis induces the 
forward and downward shift of the body's centre of mass with respect to the base of support. Consequently in AS patients the extension of the hips, flexion of the knees and plantar flexion of the ankles occur to maintain balance [7].

AS subjects may have balance alterations associated with poor posture, joint deformities, muscle atrophy and pain [8]. The reduction of the range of movement of the head and neck may worsen balance problems hampering gaze stability [9].

The primary goal in the treatment of AS patients is to reduce pain and inflammation, to prevent permanent structural damages, and to maintain the highest possible functional status and health related quality of life.

ASAS/EULAR recommendations for the management of ankylosing spondylitis state that the optimal management of AS requires a combination of pharmacological and nonpharmacological treatments. TNF blocker agents have been shown to improve significantly spinal pain, function and peripheral joint arthritis in the short term and in the long term follow up in patients with persistently high disease activity despite conventional therapies [10]. Non pharmacological treatment include patient education and exercise both individually and in groups [11]. Patient education and behavioral therapy seem to improve anxiety and motivation, but there are no evidences of their effectiveness on disease's symptoms and disability. Individual and group exercises play an important role in all stages of the disease owing to associated improvements in function and pain. Global assessment is better in AS patients involved inphysiotherapic group treatments [12]. Although benefits of combination treatment including rehabilitation and TNF inhibitors are well described in literature [13,14] current evidence shows that a specific exercise protocol has not been validated yet [12].

Feldenkrais-Core Integration (FCI) method developed by Josef Della Grotte [15] derives from Feldenkrais ${ }^{\circledR}$ method principles [16] and integrates them with the my ofascialchain concepts [17]. The concept of myofascial chain originates from the assumption that the muscles of the human body do not function as independent units. Instead, they are regarded as part of a tensegrity-like, body-wide network, with fascial structures acting as linking components [18].

Feldenkrais $₫$ method is a movement pedagogy designed to improve function in activities of daily living, work and recreation through an increasing awareness about movement habits, as well as to find alternative ways of using the body [19]. Feldenkrais® method aims to help people become self-directed learners through specific use of sensimotor experiences and exploratory processes of moving [20].

FCI approach emphasizes the importance of postural re-education, balance improvement and promotes active involvement of the patient in the rehabilitation program. It provides for a global approach in order to take care of the overall health of a patient, treating not only the districts affected, but the whole musculoskeletal system. FCI offers a new mapping system to re-organize movements and to remove incorrect motor patterns.

Although clinical studies focused on the efficacy of FCI in AS patients are still lacking, many authors show beneficial effects of Feldenkrais $®$ method in improving balance [21] and mobility [22] and in reducing pain (VAS - Visual Analogue Scale) [23] and disability (WDI- Waddell Disability Index) [24] in patients with chronic low back pain [25]. A tailored FCI intervention in posturopatic patients improved significantly the global postural score and had positive effects both on tonic postural state and dynamic postural parameters [26]. The sum of twenty-five postural parameters, assessed applying the ISTAP (The Institute of Postural Analysis, Florence, Italy) diagnostic protocol, affords the global postural score. Postural parameters were evaluated with a specific kinematic examination in addition to the assessment of static and dynamic forces while walking [27].

Based on these results, we hypothesized that FCI may have positive effects on signs and symptoms of spondyloartrhitis. Therefore in this pilot study the main aim was to evaluate the utility of FCI method in the treatment of AS patients, focusing on pain, fatigue, global health status, disability, spinal range of motion and disease activity.

\section{Materials and Methods}

\section{Subjects}

Ten AS patients, 5 men and 5 women, were recruited, consecutively from January 2016 to June 2016, from the outpatient clinic of the Division of Rheumatology, Department of Experimental and Clinical Medicine, University of Florence. Inclusion criterion was the diagnosis of ankylosing spondylitis according to modified New York criteria [6]. Patients recruited signed a written informed consent for all the procedures in accordance with Helsinki Declaration of 1975/83. The study was approved by local Ethical Committee.

All patients continued their pharmacological treatments and throughout the period of the study they were asked not to start any new pharmacological and non pharmacological therapy.

\section{Rehabilitation}

AS patients were included in a FCI physiotherapic program of 10 sessions (maximum 5-6 participants) each lasting about 60 minutes, twice a week. The lessons were conducted by a physiotherapist (LM) who is experienced and trained in FCI method. The physiotherapic protocol included home exercises chosen by the therapist and tailored on the patient, performed daily (30minutes/day) during the whole treatment period.

\section{Feldenkrais-Core integration method}

FCI intervention has at least three functional and structural outcomes: 


\section{Journal of Complementary Medicine \& Alternative Healthcare}

A. Better body organization and postural equilibrium;

B. Greater efficiency and energy conservancy;

C. Greater kinetic energy by gathering potential energy in muscles.

The main assumption of this training is that central nervous system (CNS) can best track and organize efficient movement when there is a recognition of clear direction to, and perceived connection with, functional-structural pathways. The process leads to static and dynamic equilibrium through muscular and myofascial integration. Core integration method has identified and mapped six core movement pathways to describe and account for the transmission of forces in any biomechanical system. The core pathways are a mapping construct of how the body system organizes itself through movement for appropriate functional use.

The pathway used is defined with the following concepts:

A. It contains a vector of force, direction, and myofascial tensegrity; it passes through the center of gravity and represents the most efficient expenditure of energy

B. It has specific anatomical features and can be tracked through specific joint angles, actions of levers, muscle chains and fascial tensile spread

C. It requires lengthening by virtue of mechanical levering and the physiology of myofascial actions

D. Muscles in the sequential contracting-lengthening phase stimulate tensile fascial spread $[15,26]$.

In each lesson the FCI approach consisted in:

A. Core integration (CI) group exercises aimed at strengthening deep muscle, improving body flexibility and stability. They consist in an application of a movement map based on six core movement pathways which enables the patient to organize movements with better efficiency and less expenditure of energy.

B. Feldenkrais@-based Awareness Through Movement group lessons aimed at gaining control of how the body system organizes itself through movement and constructing correct motor patterns. The key is in identifying the paths, assessing movement and posture, tracking how movement is transmitting, and determining through client response whether CNS receives and fixes the image $[15,26]$.

C. The lessons were sequential, and each lesson dealt with themes from the previous session. FCI kinetic protocol would be interrupted in case of clinical worsening (increased pain, stiffness or fatigue).

D. The exercise program proposed is further detailed in Table 1.
Table 1: Feldenkrais-Core Integration training program: exercise description and objectives.

\begin{tabular}{|c|c|}
\hline \multicolumn{2}{|c|}{ First Lesson } \\
\hline Exercise description & Objectives \\
\hline Exercises of conscious respiration & $\begin{array}{l}\text { To help maintain or improve } \\
\text { chest expansion. To help } \\
\text { relaxion and concentration on } \\
\text { training program. }\end{array}$ \\
\hline $\begin{array}{l}\text { Feldenkrais@-based Awareness } \\
\text { Through Movement group } \\
\text { exercises focused on perception } \\
\text { of the body while the subject is } \\
\text { laying on a mat. These exercises } \\
\text { are proposed at the beginning, at } \\
\text { the end of the lesson and when the } \\
\text { patients are asked to switch body } \\
\text { position. }\end{array}$ & $\begin{array}{l}\text { To enhance perception of } \\
\text { specific body segments } \\
\text { characteristics in terms } \\
\text { of dimensions, weight, } \\
\text { consistency and symmetry. }\end{array}$ \\
\hline $\begin{array}{l}\text { Self massage training session with } \\
\text { a sensory ball. }\end{array}$ & $\begin{array}{l}\text { To gain patient's perception } \\
\text { of specific body segments, } \\
\text { particularly of painful areas. }\end{array}$ \\
\hline \multicolumn{2}{|c|}{ From 2nd to 10th lesson } \\
\hline Exercise description & Objectives \\
\hline Exercises of conscious respiration & $\begin{array}{l}\text { To help maintain or improve } \\
\text { chest expansion. To help } \\
\text { relaxion and concentration on } \\
\text { training program. }\end{array}$ \\
\hline $\begin{array}{c}\text { Feldenkrais@-based Awareness } \\
\text { Through Movement exercises (see } \\
\text { first lesson) }\end{array}$ & $\begin{array}{l}\text { To enhance perception of } \\
\text { specific body segments } \\
\text { characteristics in terms } \\
\text { of dimensions, weight, } \\
\text { consistency and symmetry. }\end{array}$ \\
\hline $\begin{array}{l}\text { CI exercises in different positions } \\
\text { (supine, prone, sitting, standing, } \\
\text { crawling and lateral decubitus) } \\
\text { using elastic bands, lumbar rollers, } \\
\text { disc'o'sit inflatable cushions and } \\
\text { sensory balls. }\end{array}$ & $\begin{array}{l}\text { To identify the paths, assessing } \\
\text { movement and posture, } \\
\text { tracking how movement is } \\
\text { transmitting. To find alternative } \\
\text { ways of using the body. To } \\
\text { remove incorrect motor } \\
\text { patterns. }\end{array}$ \\
\hline \multicolumn{2}{|c|}{ Home exercises } \\
\hline Exercise description & Objectives \\
\hline Self massage with sensory ball & $\begin{array}{l}\text { To improve the patient's } \\
\text { recollection of technique and } \\
\text { exercise prescription }\end{array}$ \\
\hline CI exercises & \\
\hline
\end{tabular}

\section{Measurements}

At baseline ( $\mathrm{t}=0)$, patients were evaluated for demographic characters (sex, age), disease duration and type of joint involvement. Presence of sacroiliac pain, arthritis, enthesitis, thoracic pain, dactylitis and uveitis was also assessed. Previous physiotherapy treatments and sportive activities were evaluated. All patients were assessed by clinic and clinimetric tools at $t=0$ and at the end of the study ( $\mathrm{t}=1$ ) for pain, fatigue, global health status, effect of AS on patients' wellbeing, functional status, disability, disease activity and enthesitis. Anthropometric measurements of lumbar and cervical mobility were also documented. At the end of the physiotherapic treatment $(\mathrm{t}=1)$ patients' satisfaction, attendance rate and attrition rate were assessed. 


\section{Journal of Complementary Medicine \& Alternative Healthcare}

\section{Clinic and clinimetric measurements}

A. Pain was rated with an auto-administered Visual Analogue Scale (VAS 0-10), which measures current pain intensity on a $0-10$ scale $(0=$ no pain, $10=$ worst pain [23]).

B. Fatigue was rated with an auto-administered Visual Analogue Scale (VAS 0-10), which measures current fatigue intensity on a $0-10$ scale $(0=$ no fatigue, $10=$ worst fatigue).

C. Global health status was rated with an autoadministered Visual Analogue Scale (VAS 0-10), which measures current global health status intensity on a 0-10 scale ( $0=$ worst health status, $10=$ best health status).

Disease effect on wellbeing was rated by Italian version of Bath Ankylosing Spondylitis Global Score (BAS-G) which asks patients to indicate the effect of AS on their well-being over the last week and the last 6 months, using a $100 \mathrm{~mm}$ horizontal visual analogue scale, where none $=0$ and very severe $=100$. The mean of the two scales affords the BAS-G score a value between 0 and 100, with a lower score indicating less disease burden [28].

Functional status was rated by Italian version of Bath Ankylosing Spondylitis Functional Index (BASFI) which is composed by ten questions elaborated to determine the degree of functional limitation in patients with AS. Each question is answered using an 11-points numerical rating scale (NRS), with a recall period of the past week. The mean of the ten scales affords the BASFI score a value between 0 and 100, with a lower score indicating less functional limitation [29,30].

Disability was rated by Italian version of Health Assessment Questionnaire-Spondyloarthropathies (HAQ-S) which is a selfreport questionnaire referring to global disability, ranges from 0 (no difficulty) to 3 (unable to do) [31].

Disease activity was rated by Italian version of Bath Ankylosing Spondylitis Disease Activity Index (BASDAI) which has six 11-points NRS to measure the severity of fatigue, spinal and peripheral joint pain, localized tenderness, and morning stiffness in patients with AS. Each item is provided using a 0-100 horizontal NRS, to extremes the adjectival descriptors "none" and "very severe". Item six (duration of morning stiffness) is related to a time scale $(0-2 \mathrm{~h})$. The mean of items five (severity of morning stiffness) and six is calculated separately. The BASDAI, a number from 0 to 100 , is obtained with the mean of this result with the previous four items. Lower scores are indicating lower disease activity. The cut-off of four is used to define the presence of an active disease [32].

Enthesitis was documented by Maastricht Ankylosing Spondylitis Enthesitis Score (MASES) which evaluates the presence or the absence of tenderness in 13 enthesial sites Tenderness on physical examination is recorded as either present (1) or absent ( 0 ) for each of the 13 sites, for an overall score range of $0-13$ [33].

\section{Anthropometric measurements}

\section{Lumbar mobility}

A. Forward flexion was documented by Schöber test and finger floor distance (FFD).

Schöber test - Two reference points (spinous process of L5 and $10 \mathrm{~cm}$ above) were marked on the patients' low back region while they stood in erect position with feet together. Then the patients bent maximally forward and the new distance between the upper and lower marks was measured. Distances of 14.5-15 cm are considered normal [34]. FFD - The patients bent maximally forward trying to touch the floor. The distance between fingers and floor was reported (cm).

B. Lateral flexion - The patients bent laterally to the right and to the left. The distance between fingers and floor was reported for each side $(\mathrm{cm})$.

\section{Cervical mobility}

A. Flexion and extension of the head: The patients bent the head maximally forward and backward. The distances between chin and suprasternal notch were reported $(\mathrm{cm})$.

B. Lateral flexion of the head: The patients bent the head laterally to the right and to the left. The distance between tragus and acromion process were reported for each side (cm).

C. Head rotation: The patients rotated maximally the head to the right and to the left. The distance between chin and acromion process were reported for each side $(\mathrm{cm})$.

\section{Patient's feedback}

Patient satisfaction with physiotherapic treatment was evaluated with a questionnaire measuring seven items (self perceived wellbeing, pain and stiffness reduction, movement fluency and easiness, enjoyableness of the physiotherapic program and willingness to continue the treatment) each one rated with an auto-administered Visual Analogue Scale (VAS), reporting the measure on a $0-10$ scale $(0=$ no satisfaction, 10 =best satisfaction). The overall satisfaction, a number from 0 to 70 , is obtained summing VAS scores of the previous seven items. Lower scores are indicating lower satisfaction. Attendance rate was reported as total hours of patients' attendance/total hours patients' treatment ratio (\%); Attrition rate was reported as Dropouts/Patients recruited ratio (\%).

\section{Data analysis}

Descriptive statistics for nominal data were expressed in percentages. Continuous variables were described as mean and standard deviation $(\mathrm{M} \pm \mathrm{SD}$ ). To assess improving parameters over the period of study differences between means and percentage changes were evaluated (SPSS statistical package, version 20.0 for Windows, SPSS, Chicago, USA) 


\section{Journal of Complementary Medicine \& Alternative Healthcare}

\section{Results}

Table 2: Baseline and demographic characteristics for the patients enrolled.

\begin{tabular}{|c|c|c|}
\hline & Mean \pm SD & Min-max \\
\hline Age (years) & $55,30 \pm 12,05$ & $(32-72)$ \\
\hline $\begin{array}{c}\text { Disease duration } \\
\text { (years) }\end{array}$ & $18,60 \pm 18,63$ & Numbers and Percentages \\
\hline Gender (M/F) & $5 / 5(50 \%)$ \\
\hline Occupation & $7 / 10 / 70 \%)$ \\
\hline $\begin{array}{c}\text { Previous sportive } \\
\text { activities }\end{array}$ & $3 / 10(30 \%)$ \\
\hline $\begin{array}{c}\text { Previous } \\
\text { physiotherapy } \\
\text { treatments }\end{array}$ & $6 / 10(60 \%)$ \\
\hline
\end{tabular}

\begin{tabular}{|c|c|}
\hline $\begin{array}{c}\text { Joint involvement: } \\
\bullet \text { axial }\end{array}$ & $6 / 10(60 \%)$ \\
\hline p peripheral & $2 / 10(20 \%)$ \\
\hline axial-peripheral & $2 / 10(20 \%)$ \\
\hline Sacroliliac pain & $8 / 10(80 \%)$ \\
\hline Arthritis & $4 / 10(40 \%)$ \\
\hline Enthesitis & $6 / 10(60 \%)$ \\
\hline Thoracic pain & $3 / 10(30 \%)$ \\
\hline Dactylitis & $2 / 10(20 \%)$ \\
\hline Uveitis & $1 / 10(10 \%)$ \\
\hline
\end{tabular}

Table 3: Clinic and clinimetric evaluations at baseline $(t=0)$ and at the end of the treatment $(t=1)$. Differences in mean evaluations between $t=0$ and $\mathrm{t}=1$. Percentage changes between $\mathrm{t}=0$ and $\mathrm{t}=1$.

\begin{tabular}{|c|c|c|c|c|}
\hline & $\begin{array}{l}\text { Mean (ds) } \\
\quad t=0\end{array}$ & $\begin{array}{c}\text { Mean (ds) } \\
\quad t=1\end{array}$ & $\begin{array}{c}\text { Mean (ds) } \\
\text { Delta (t1-t0) }\end{array}$ & $\begin{array}{c}\text { Percentage changes } \\
\text { (t1-t0) }\end{array}$ \\
\hline VAS Pain & $3,80 \pm 2,34$ & $3,39 \pm 2,38$ & $-0,41 \pm 1,20$ & $10,79 \%$ \\
\hline VAS Fatigue & $4,37 \pm 2,63$ & $3,49 \pm 2,10$ & $-0,88 \pm 1,60$ & $20,14 \%$ \\
\hline VAS Global health status & $4,32 \pm 2,60$ & $5,32 \pm 2,51$ & $1,00 \pm 3,47$ & $23,15 \%$ \\
\hline BAS-G & $43,50 \pm 19,78$ & $36,00 \pm 27,72$ & $-7,5 \pm 20,09$ & $17,24 \%$ \\
\hline BASFI & $22,95 \pm 15,83$ & $19,9 \pm 19,2$ & $-3,05 \pm 13,78$ & $13,29 \%$ \\
\hline HAQ-S & $0,48 \pm 0,52$ & $0,44 \pm 0,72$ & $-0,47 \pm 0,36$ & $8,33 \%$ \\
\hline BASDAI & $42,35 \pm 16,45$ & $40,91 \pm 19,89$ & $-1,44 \pm 13,67$ & $3,40 \%$ \\
\hline MASES & $4,33 \pm 4,03$ & $3,50 \pm 4,09$ & $-0,80 \pm 1,62$ & $19,17 \%$ \\
\hline Schöber Test (cm) & $2,20 \pm 1,51$ & $2 \pm 1,70$ & $-0,20(0,92)$ & Not improved \\
\hline $\begin{array}{l}\text { Lumbar lateral flexion } \\
\text { (right) }(\mathrm{cm})\end{array}$ & $53,10 \pm 5,92$ & $52,70 \pm 6,40$ & $-0,40 \pm 2,27$ & $0,75 \%$ \\
\hline $\begin{array}{l}\text { Lumbar lateral flexion } \\
\text { (left) }(\mathrm{cm})\end{array}$ & $54,30 \pm 6,18$ & $53,60 \pm 6,33$ & $-0,70 \pm 1,50$ & $1,29 \%$ \\
\hline $\begin{array}{l}\text { Lumbar forward flexion } \\
\qquad(\mathrm{cm})\end{array}$ & $20,95 \pm 18,66$ & $22,90 \pm 16,24$ & $1,95 \pm 12,09$ & Not improved \\
\hline $\begin{array}{l}\text { Cervical forward flexion } \\
\qquad(\mathrm{cm})\end{array}$ & $3,85 \pm 3,68$ & $3,70 \pm 3,71$ & $-0,15 \pm 1,70$ & $3,90 \%$ \\
\hline Cervical extension $(\mathrm{cm})$ & $17,30 \pm 2,11$ & $17,80 \pm 2,04$ & $0,50 \pm 1,55$ & $2,89 \%$ \\
\hline $\begin{array}{l}\text { Cervical lateral flexion } \\
\text { (right) (cm) }\end{array}$ & $15 \pm 2,54$ & $14,85 \pm 1,20$ & $-0,15 \pm 2,00$ & $1,00 \%$ \\
\hline $\begin{array}{l}\text { Cervical lateral flexion } \\
\text { (left) }(\mathrm{cm})\end{array}$ & $14,85 \pm 2,60$ & $15,55 \pm 1,50$ & $0,70 \pm 2,31$ & Not improved \\
\hline $\begin{array}{l}\text { Cervical rotation (right) } \\
(\mathrm{cm})\end{array}$ & $16,60 \pm 4,40$ & $16,20 \pm 2,69$ & $-0,40 \pm 2,28$ & $2,41 \%$ \\
\hline $\begin{array}{l}\text { Cervical rotation (left) } \\
\text { (cm) }\end{array}$ & $17 \pm 4,16$ & $16,45 \pm 2,83$ & $-0,55 \pm 2,17$ & $3,24 \%$ \\
\hline
\end{tabular}




\section{Journal of Complementary Medicine \& Alternative Healthcare}

Ten AS patients, 5 men and 5 women, were enrolled and assessed. Their baseline characteristics are summarized in Table 2. The differences between the means of the clinical and clinimetric evaluations at $\mathrm{t}=0$ and at $\mathrm{t}=1$ show that $\mathrm{FCI}$ physiotherapic sessions had positive effects on pain, fatigue, global health status, BAS-G, BASFI, HAQ-S, BASDAI, MASES, lumbar (lateral flexion) and cervical mobility (flexion/extension, lateral flexion and lateral rotation of the head) (Table 3). The adherence to FCI physiotherapic program was complete. No dropouts were registered. The attendance rate was $78,6 \%$. The patients' satisfaction score was 58,0 $\pm 6,75$.

\section{Discussion}

AS is a systemic, chronic rheumatic disease that predominantly affects axial skeleton with severe sacroiliac pain and impaired spinal mobility leading to disability [35] and reduced quality of life [3]. Modifications in spinal posture begin at early stages of the disease and become more marked over the time [36] and account for balance problems [37]. The optimal management of AS requires a combination of tailored pharmacologic and nonpharmacologic interventions aiming at treating inflammation and pain, preventing structural deformities, increasing spinal motion [10,12] and improve overall function and quality of life [38]. Despite the evidences about the effectiveness of physiotherapy in AS, a specific physical exercise protocol has not been established yet [39].

Global Posture Reeducation (GPR) method, a form of active overall muscle stretching working on strengthening and improving flexibility of specific muscle chains offered promising results in restoring spinal mobility (BASMI) and functional capacity (BASFI) in AS patients group sessions managed by a trained physiotherapist [40]. GPR group intervention demonstrated to maintain improved parameters after 6 months and one year follow-up [41]. GPR individual treatment in AS showed significantly greater improvement in morning stiffness duration, spinal mobility parameters (chin to chest distance, occiput to wall distance, cervical rotation, modified Schöber test [42]), chest expansion and self perceived physical wellbeing (SF36 - Short Form 36 Health Survey [43]) than the control group treated with segmental stretching and breathing exercises [44].

Pilates body conditioning method, a well known formula of over 500 physical exercises focusing on stretching and strengthening body core muscles [45] was suggested as a beneficial exercise therapy in patients with musculoskeletal spinal problems increasing proprioceptive balance (Stork stand test) and flexibility (Sit and reach test) [46], reducing disability (OSWDQ - Oswestry Low Back Pain DisabilityQuestionnaire [47]) and pain intensity (VAS) [48,49]. In AS patients Pilates showed positive outcomes on chest expansion, Bath Ankylosing Spondylitis Metrology Index (BASMI) and BASDAI in a short term follow up, and significant improvements of functional status and BASMI after 6 months compared to the baseline [50].

In a recent study involving early AS patients in a specific McKenzie kinetic program aimed at assessing and treating spinal and postural problems, significant improvements in pain, metrology (BASMI, FFD, chest expansion, modified Schöber test), function (BASFI) and disease activity (BASDAI) were registered compared to the baseline and to the control group [51]. Moreover a specific protocol combining McKenzie, Pilates \& Heckscher [52] conducted in a group setting and followed by a maintaining home exercise regimen registered significantly beneficial effects on pain, spinal mobility, BASDAI, BASMI and chest expansion in AS patients [53].

Aquatic exercises have been used for many years in the treatment of musculoskeletal conditions. In this context hydrotherapy effectiveness is widely reported [54]. The benefits of aquatic exercise arise from the physiological effects of immersion and hydrodynamic principles of exercise in the aquatic environment [55-57]. An in-patient rehabilitation program including hydrotherapy, basic exercises for movement, muscle strength and stability, balance and coordination improved disease activity (BASDAI), spinal mobility (BASMI, FFD), chest expansion and gait velocity ( $6 \mathrm{~m}$ gait velocity test) in AS patients [58]. A randomized trial exploring three exercise regimens in AS showed beneficial effects of hydrotherapy on pain and stiffness. However any significant improvement was found at 6 months follow up [59].

Feldenkrais Core Integration method is a somatic rehabilitation technique with low physical impact and few side effects. FCI is counted among mind body therapies (MBT) and is focused on gaining perception and body awareness in order to recognize and correct abnormalities such as muscle contractions and posture misalignments and consequently to reduce antalgic and non functional posture. Several studies demonstrate that MBT, increasing the abilities of the mind to influence body characteristics and disease symptoms, are effective and useful in the rehabilitation of chronic rheumatic patients, especially in improving function, pain and reducing social and psychological problems [60-63]. Despite their potential utility, few MBT were evaluated in AS.

The present study is the first aimed at assessing the feasibility and the utility of Feldenkrais Core Integration method in the treatment of AS. Our results showed improvements in pain, fatigue, global health status, BASDAI, BAS-G, BASFI, MASES, HAQ-S, lumbar lateral flexion and cervical range of motion (cervical forward flexion, extension, lateral flexion and rotation) at the end of the study compared to the baseline. Greater improvements in percentage are found in pain, fatigue, self perceived health status, functionality and tenderness on enthesial sites. This suggests the utility of FCI in improving flexibility and movement fluency and in re-organizing body schemas trying to eliminate antalgic postures. Effects on clinimetric parameters were scanty probably due to the short duration of the physiotherapic interventions and the exiguous number of sessions performed. Moreover the wide range of disease duration in our sample may explain the different response to the therapy and may affect the results of the study. 


\section{Journal of Complementary Medicine \& Alternative Healthcare}

FCI method provides for a global approach and focuses on the close relationships between mental and somatic dimensions [15]. Therefore it allows to reach physical and emotional well-being and to increase the patient's overall health. Our results seemed to confirm these concepts, in fact the greatest improvement in percentage was found in self perceived global health status.

FCI, characterized by low physical impact approach, is always respectful of the pain threshold. These latter guarantees a high adherence to the rehabilitation program and reduces the probability of dropouts. In fact in our study no dropouts were registered and the patients' satisfaction was adequate.

Owing the exploratory nature of the present study, the small sample size and the short term intervention, inferential statistical tests were not performed. Further investigations on wider cohorts of patients and longitudinal design are required to confirm the utility of FCI as an important rehabilitation tool in AS.

\section{Conclusion}

Feldenkrais Core Integration method is a movement based MBT with potential effects on muscle contractures, pain and stiffness. Its global approach recognizes the interactions between mind and body in supporting health and allows the patients to achieve physical and psychological wellbeing. The present study showed that FCI approach may be a useful and feasible non-pharmacologic approach in the treatment of patients with ankylosing spondylitis. FCI had positive effects on pain, fatigue, global health status, disease activity, functional status and enthesitis. Our results should be validated by prospective studies with larger sample size.

\section{Conflict of Interest}

No financial supports or any other benefit, which could create a potential conflict of interest with regard to the work, are declared.

\section{References}

1. Braun J, Sieper J. (2007) Ankylosing spondylitis. Lancet 369(9570): 1379-1390.

2. van Echteld I, Cieza A, Boonen A, Stucki G, Zochling J, et al. (2006) Identification of the most common problems by patients with ankylosing spondylitis using the international classification of functioning, disability and health. J Rheumatol: 33(12): 2475-2483.

3. Sieper J, Braun J, Rudwaleit M, Boonen A, Zink A (2002) Ankylosing spondylitis: an overview. Ann Rheum Dis: 61 Suppl III: 8-18.

4. Salaffi F, De Angelis R, Grassi W (2005) M Arche Pain Prevalence; INvestigation Group (MAPPING) study. Prevalence of musculoskeletal conditions in an Italian population sample: results of a regional community-based study. I. The MAPPING study ClinExpRheumatol 23(6): 819-828

5. Swinkels A, Dolan P (2004) Spinal Position Sense and Disease Progression in Ankylosing Spondylitis, A Longitudinal Study. Spine 29(11): 1240-1245

6. van der Linden S, Valkenburg HA, Cats A (1984) Evaluation of diagnostic criteria for ankylosing spondylitis. A proposal for modification of the New York criteria. Arthritis Rheum 27(4): 361-815.
7. Pompeu JE, Romano RS, Pompeu SM, Lima SM (2012) Static and dynamic balance in subjects with ankylosing spondylitis: literature review. Rev Bras Reumatol 52(3): 409-416.

8. Sawacha Z, Carraro E, Del Din S, Guiotto A, Bonaldo L, et al. (2012) Biomechanical assessment of balance and posture in subjects with ankylosing spondylitis. J Neuroeng Rehabil 9: 63.

9. Murray HC, Elliott C, Barton SE, Murray A (2000) Do patients with ankylosing spondylitis have poorer balance than normal subjects? Rheumatology (Oxford) 39(5): 497-500.

10. Zochling J, van der Heijde D, Burgos-Vargas R, Collantes E, Davis JC Jr, et al. (2006) ASAS/EULAR recommendations for the management of ankylosing spondylitis. Rheum Dis 65(4): 442-452.

11. Wendling D, Lukas C, Paccou J, et al. (2014) French Society for Rheumatology (SFR): Recommendations of the French Society for Rheumatology (SFR) on the everyday management of patients with spondyloarthritis. Joint Bone Spine: 81: 6-14.

12. Dagfinrud H, Kvien TK, Hagen KB (2008) Physiotherapy interventions for ankylosing spondylitis. Cochrane Database Syst Rev 23(1): CD002822.

13. Fongen C, Halvorsen S, Dagfinrud H (2013) High disease activity is related to low levels of physical activity in patients with ankylosing spondylitis. ClinRheumatol 32: 1719-1725.

14. Lubrano E, D’Angelo S, Parsons WJ, Serino F, Tanzillo AT, et al. Effects of a combination treatment of an intensive rehabilitation program and etanercept in patients with ankylosing spondylitis: a pilot study. J Rheumatol 33(10): 2029-2034.

15. Della Grotte J (2007) Instructions From Within: Six Primary Core Pathways. CITI. Library of Congress, Washington, DC.

16. Feldenkrais M (1990) Awareness Through Movement - Easy-todo Health Exercises to Improve Your Posture, Vision, Imagination and Personal Awareness (paperback ed.) 1990, Harper Collins, San Francisco, USA.

17. Myers TW (2014) Anatomy trains: myofascial meridians for manual and movement therapists ( $3^{\text {rd }}$ edn), Churchill Livingstone, New York, USA.

18. Wilke J, Krause F, Vogt L, Banzer W (2016) What Is Evidence-Based About Myofascial Chains: A Systematic Review. Arch Phys Med Rehabil 97(3): 454-461.

19. Buchanan PA, Ulrich BD (2001) The Feldenkrais method: a dynamic approach to changing motor behaviour. Res Q Exerc Sport 72(4): 315323.

20. Ohman A, Aström L, Malmgren-Olsson EB (2011) Feldenkrais® therapy as group treatment for chronic pain-a qualitative evaluation. J Bodyw Mov Ther 15(2): 153-161.

21. Stephens J, DuShuttle D, Hatcher C, Shmunes J, Slaninka C (2001) Use of awareness through movement improves balance and balance confidence in people with multiple sclerosis: a randomized controlled study. Neurology Report 25(2): 39-49.

22. Ullmann G, Williams HG, Hussey J, Durstine JL, McClenaghan BA (2010) Effects of Feldenkrais exercises on balance, mobility, balance confidence, and gait performance in community-dwelling adults age 65 and older. J Altern Complement Med 16(1): 97-105.

23. Burckhardt CS, Jones KD (2003) Adult measures of pain: The McGill Pain Questionnaire (MPQ), Rheumatoid Arthritis Pain Scale (RAPS), Short-Form McGill Pain Questionnaire (SF-MPQ), Verbal Descriptive Scale(VDS), Visual Analog Scale (VAS), and West Haven-Yale Multidisciplinary Pain Inventory (WHYMPI). Arthritis Rheum 49: S96-S104.

24. Waddell G, Main CJ (1984) Assessment of severity in low-back disorders. Spine 9(2): 204-208. 


\section{Journal of Complementary Medicine \& Alternative Healthcare}

25. Paolucci T, Zangrando F, Iosa M, De Angelis S, Marzoli C, et al. (2016) Improved interoceptive awareness in chronic low back pain: a comparison of Back school versus Feldenkrais method. Disabil Rehabil 23: $1-8$.

26. DellaGrotte J, Ridi R, Landi M, Stephens J (2008) Postural improvement using core integration to lengthen myofascia. Journal of Bodywork and Movement Therapies 12: 231-245.

27. Ridi R, Rossi F, Puglisi F (2003) Quindicianni di ricercamultidisciplinare in campo posturologico: definizion edegliambiti di studio e deiprotocolliclinico-instrumentali. Terapia Manuale \& Riabilitazione, Anno 5-n1.

28. Jones SD, Steiner A, Garrett SL, Calin A (1996) The Bath Ankylosing Spondylitis Patient Global Score (BAS-G). Br J Rheumatol 35(1): 66-71.

29. Calin A, Garrett S, Whitelock H, Kennedy LG, O’Hea J, et al. (1994) A new approach to defining functional ability in ankylosing spondylitis: the development of the bath ankylosing spondylitis functional index. Rheumatol 21(12): 2281-2285.

30. Salaffi F, Stancati A, Silvestri A, Carotti M, Grassi W (2005) Validation of the Italian versions of the Bath Ankylosing Spondylitis Functional Index (BASFI) and the Dougados Functional Index (DFI) in patients with ankylosing spondylitis, Reumatismo 57(3): 161-173.

31. Daltroy LH, Larson MG, Roberts WN (1990) A modification of the Health Assessment Questionnaire for the Spondyloarthropathies, Rheumatol 17(7): 946-950.

32. Garrett S, Jenkinson T, Kennedy LG, Whitelock H, Gaisford P, et al. (1994) A new approach to defining disease status in ankylosing spondylitis: the bath ankylosing spondylitis disease activity index. J Rheumato 21(12): 2286-2291.

33. Heuft-Dorenbosch L, Spoorenberg A, van Tubergen A, Landewe R, vanverTempel $\mathrm{H}$, et al. (2003) Assessment of enthesitis in ankylosing spondylitis. Ann Rheum Dis 62(2): 127-132.

34. Schober P (1937) The lumbar vertebral column and backache. Munch Med Wschr 84: 336

35. Sieper J, Rudwaleit M, Baraliakos X, Brandt J, Braun J, et al. (2009) The Assessment of SpondyloArthritis International Society (ASAS) handbook: a guide to assess spondyloarthritis. Ann Rheum Dis 68(Suppl 2): ii1-ii44.

36. Aydog E, Depedibi R, Bal A, Eksioglu E, Unlu E, et al. (2006) Dynamic postural balance in ankylosing spondylitis patients. Rheumatology 45(4): 445-448.

37. Bot SDM, Caspers M, Van Royen BJ, Toussaint HM, Kingma I (1999) Biomechanical analysis of posture in patients with spinal kyphosis due to ankylosing spondylitis: a pilot study. Rheumatology 38(5): 441-443.

38. Passalent LA (2011) Physiotherapy for ankylosing spondylitis: evidence and application. Curr Opin Rheumatol 23(2): 142-147.

39. Giannotti E, TrainitoS, Arioli G, Rucco V, Masiero S (2014) Effects of physical therapy for the management of patients with ankylosing spondylitis in the biological era. ClinRheumatol 33(9): 1217-1230.

40. Fernandez-de-Las Penas C, Alonso-Blanco C, Morales-Cabezas M Miangolarra-Page JC (2005) Two exercise interventions for the management of patients with ankylosing spondylitis: a randomized controlled trial. Am J Phys Med Rehabil 84(6): 407-419.

41. Fernandez-de-Las-Penas C, Alonso-Blanco C, Alguacil-Diego IM, Miangolarra-Page JC (2006) One-year follow-up of two exercise interventions for the management of patients with ankylosing spondylitis: a randomized controlled trial. Am I Phys Med Rehabil 85(7): 559-567.

42. Jenkinson TR, Mallorie PA, Whitelock HC, Kennedy LG, Garrett SL, et al. (1994) Defining spinal mobility in ankylosing spondylitis (AS). The Bath AS Metrology Index. J Rheumatol 21(9): 1694-1698.
43. Ware JE, Snow KK, Kosinski M, Gandek B (1993) SF-36® Health Survey Manual and Interpretation Guide. New England Medical Center, The Health Institute, Boston, MA, USA.

44. Silva EM, Andrade SC, Vilar MJ (2012) Evaluation of the effects of Global Postural Reeducation in patients with ankylosing spondylitis. Rheumatol Int 32(7): 2155-2163.

45. Friedman P, Eisen G (2005) The pilates method of Physical and mental conditioning (10 th $e d n)$. Penguin books ltd, London, England, pp. 190.

46. Gladwell V, Head S, Haggar M, Beneke R (2006) Does a program of Pilates improve chronic no-specific low back pain. J Sport Rehabil 15: 338-350.

47. Fairbank JC, Couper J, Davies JB, O'Brien JP (1980) The Oswestry low back pain disability questionnaire. Physiotherapy 66(8): 271-273.

48. Posadzki P, Lizis P, Hagner-Derengowska M (2011) Pilates for low back pain: a systematic review. Complement Ther Clin Pract 17(2): 85-89.

49. La Touche R, Escalante K, Linares MT (2008) Treating non-specific chronic low back pain through the Pilates Method. J Body Mov Ther 12(4): 364-370.

50. Altan L, Korkmaz N, Dizdar M, Yurtkuran M (2012) Effect of Pilates training on people with ankylosing spondylitis. RheumatolInt 32(7): 2093-2099.

51. Rosu MO, Ancuta C (2015) McKenzie training in patients with early stages of ankylosing spondylitis: results of a 24-week controlled study. Eur J PhysRehabilMed 51(3): 261-268.

52. Heckscher H, Elliot R (1959) Gimnastiquedans les insuffisances respiratoire chronique. Masson, Paris.

53. Rosu MO, Ţopa I, Chirieac R, Ancuta C (2014) Effects of Pilates, McKenzie and Heckscher training on disease activity, spinal motility and pulmonary function in patients with ankylosing spondylitis: a randomized controlled trial. Rheumatol Int 34(3): 367-372.

54. Waller B, Lambeck J, Daly D (2009) Therapeutic aquatic exercise in the treatment of low back pain: a systematic review. Clin sRehabil 23(1): 3-14.

55. Becker BE (2009) Aquatic therapy: scientific foundations and clinical rehabilitation applications. PM R 1(9): 859-872.

56. Batterham SI, Heywood S, Keating JL (2011) Systematic review and meta-analysis comparing land and aquatic exercise for people with hip or knee arthritis on function, mobility and other health outcomes. BMC Musculoskelet Disord 12: 123.

57. McVeigh JG, McGaughey H, Hall M, Kane P (2008) The effectiveness of hydrotherapy in the management of fibromyalgia syndrome: a systematic review. Rheumatol Int 29(2): 119-130.

58. Eppeland SG, Diamantopoulos AP, Soldal DM, Haugeberg G (2013) Short term in-patient rehabilitation in axial spondyloarthritis - the results of a 2 -week program performed in daily clinical practice. BMC Res Notes 6: 185

59. Helliwell P, Abbott CA, Chamberlain MA (1996) A randomised trial of three different physiotherapy regimes in ankylosing spondylitis. Physiotherapy 82(2): 85-90.

60. Yocum DE, Castro WL, Cornett M (2000) Exercise, education, and behavioral modification as alternative therapy for pain and stress in rheumatic disease. Rheum Dis Clin North Am 26(1): 145-159, x-xi.

61. Del Rosso A, Maddali-Bongi S (2016) Mind body therapies in rehabilitation of patients with rheumatic diseases. Complement Ther Clin Pract 22: 80-86.

62. MaddaliBongi S, Paoletti G, Calà M, Del RossoA, El Aoufy K, Mikhaylova S (2016) Efficacy of rehabilitation with Tai JiQuan in an Italian cohort of patients with Fibromyalgia Syndrome. Complement Ther Clin Pract 24: 109-115. 
63. MaddaliBongi S, Del Rosso A, Di FeliceC, Calà M, Giambalvo Dal Ben G (2012) Rességuier method and Qi Gong sequentially integrated in patients with fibromyalgia syndrome. Clin Exp Rheumatol 30(6 Suppl 74): 51-58.

Your next submission with JuniperPublishers will reach you the below assets

- Quality Editorial service

- Swift Peer Review

- Reprints availability

- E-prints Service

- Manuscript Podcast for convenient understanding

- Global attainment for your research

- Manuscript accessibility in different formats ( Pdf, E-pub, Full Text, audio)

- Unceasing customer service

Track the below URL for one-step submission https://juniperpublishers.com/online-submission.php 